\title{
Complejidad, incertidumbre y vulnerabilidad: el riesgo asociado al volcán Cotopaxi en el Valle de los Chillos (Quito-Ecuador)
}

Complexité, incertitude et vulnérabilité : le risque lié au volcan Cotopaxi dans la vallée de Los Chillos (Quito-Équateur)

Complexity, uncertainty and vulnerability: the risk associated to the Cotopaxi Volcano in Los Chillos valley (Quito-Ecuador)

Jérémy Robert, Robert D'Ercole, Patrick Pigeon y Tania Serrano

\section{(2) OpenEdition}

Journals

Edición electrónica

URL: http://journals.openedition.org/bifea/2408

DOI: 10.4000/bifea.2408

ISSN: 2076-5827

\section{Editor}

Institut Français d'Études Andines

\section{Edición impresa}

Fecha de publicación: 1 diciembre 2009

Paginación: 709-733

ISSN: 0303-7495

Referencia electrónica

Jérémy Robert, Robert D’Ercole, Patrick Pigeon y Tania Serrano, « Complejidad, incertidumbre y vulnerabilidad: el riesgo asociado al volcán Cotopaxi en el Valle de los Chillos (Quito-Ecuador) », Bulletin de l'Institut français d'études andines [En línea], 38 (3) | 2009, Publicado el 01 junio 2010, consultado el 17 noviembre 2020. URL : http://journals.openedition.org/bifea/2408 ; DOI : https:// doi.org/10.4000/bifea.2408

\section{(c) $(1) \odot$}

Les contenus du Bulletin de l'Institut français d'études andines sont mis à disposition selon les termes de la licence Creative Commons Attribution - Pas d'Utilisation Commerciale - Pas de Modification 4.0 International. 


\title{
Complejidad, incertidumbre y vulnerabilidad: el riesgo asociado al volcán Cotopaxi en el Valle de los Chillos (Quito-Ecuador)
}

\author{
Jérémy Robert* \\ Robert D'Ercole** \\ Patrick Pigeon ${ }^{* * *}$ \\ Tania Serrano****
}

\begin{abstract}
Resumen
El artículo propone un análisis del riesgo asociado al volcán Cotopaxi en el Valle de Los Chillos, situado al sureste de la aglomeración urbana de Quito. En un primer momento este artículo presenta un riesgo a priori cuantificable. Sin embargo, este enfoque es cuestionado por el reconocimiento de las incertidumbres que traducen un riesgo complejo. La complejidad está ligada a las dificultades de evaluación de la amenaza pero también a la evolución de la urbanización, al manejo político de los territorios o a la variedad de la población expuesta. La exploración de los diferentes factores de complejidad del riesgo y de las incertidumbres asociadas permite mejorar la comprensión de la vulnerabilidad. Este enfoque abre también perspectivas y la reducción de las incertidumbres aparece como una herramienta de reducción de los riesgos y de ayuda para el manejo de crisis.
\end{abstract}

Palabras clave: riesgo, vulnerabilidad, complejidad, incertidumbre, manejo de crisis, Valle de Los Chillos, Cotopaxi

* Institut Français d'Études Andines (IFEA, UMIFRE 17, CNRS-MAEE), programa Pacivur: Av. Arequipa 4500, Miraflores, Casilla 18-1217, Lima 18, Perú; Université de Savoie, CISM, Laboratorio Edytem (CNRS). E-Mail: jeremy.robert@univ-savoie.fr

** Institut de Recherche pour le Développement (IRD), UR 029, programa Pacivur, Calle Teruel 357, Miraflores, Casilla 18-1209, Lima 18, Perú. E-mail: robert.dercole@ird.fr

*** Profesor de Geografía, Université de Savoie, CISM, Laboratorio Edytem (CNRS), 73376 Le Bourgetdu-Lac CEDEX, Francia. E-mail: Patrick.Pigeon@univ-savoie.fr

**** Equipo PAUD (Por el Ambiente Urbano y el Desarrollo). Becaria del IFEA (UMIFRE 17, CNRSMAEE) en 2007. E-mail: tania.catalina@gmail.com 


\title{
Complexité, incertitude et vulnérabilité : le risque lié au volcan Cotopaxi dans la vallée de Los Chillos (Quito-Équateur)
}

\begin{abstract}
Résumé
L'article propose une analyse du risque lié au volcan Cotopaxi dans la vallée de Los Chillos (Valle de Los Chillos), située au sud-est de l'agglomération urbaine de Quito. Il présente dans un premier temps un risque a priori quantifiable. Cette approche est cependant remise en cause par la reconnaissance des incertitudes, traduisant un risque complexe. La complexité est liée aux difficultés d'évaluation de I'aléa, mais aussi à l'évolution de l'urbanisation, à la gestion politique des territoires ou encore à la variabilité de la population exposée. L'exploration des différents facteurs de complexité du risque et des incertitudes qui lui sont associées permet d'améliorer la compréhension de la vulnérabilité. Cette approche ouvre aussi des perspectives : la réduction des incertitudes apparait comme un outil de réduction des risques et d'aide à la gestion de crise.
\end{abstract}

Mots clés : risque, vulnérabilité, complexité, incertitude, gestion de crise, Valle de Los Chillos, Cotopaxi

\section{Complexity, uncertainty and vulnerability: the risk associated to the Cotopaxi Volcano in Los Chillos valley (Quito-Ecuador)}

\begin{abstract}
The article proposes an analysis of the risk associated with the Cotopaxi volcano in Los Chillos valley (Valle de Los Chillos), on the south east side of metropolitan Quito. At first examination it presents a priori a quantifiable risk. However the recognition of uncertainties, which reveal risk complexity, challenged this approach. Complexity is linked not only to the difficulties of hazard evaluation, but also to urban evolution, political management of territories or exposed population variability. The exploration of various risk complexity factors and associated uncertainties improves the understanding of vulnerability. This approach also opens perspectives and the reduction of uncertainties appears as a way to reduce risk and improve crisis management tools.
\end{abstract}

Key words: risk, vulnerability, complexity, uncertainty, crisis management, Valle de Los Chillos, Cotopaxi

\section{INTRODUCCIÓN}

Es obvia la complejidad de los riesgos por la propia dificultad que tenemos en encararlos, y esto a pesar de los progresos realizados en conocimientos y técnicas. La complejidad contribuye además a aumentar la vulnerabilidad de los bienes y de las personas frente a futuros desastres. Por vulnerabilidad entendemos la propensión de un elemento (o de un conjunto de elementos) a sufrir daños en caso de manifestación de un fenómeno destructor, y a generar las condiciones propicias para su ocurrencia y/o para el aumento de sus efectos ( $\mathrm{D}^{\prime}$ Ercole et al., 2009). Por un lado, la complejidad del riesgo dificulta la cuantificación de la propensión de un elemento (o de un conjunto de elementos) a sufrir daños. 
Por otro lado, la generación de las condiciones propicias para la ocurrencia de estos fenómenos, o para el incremento de sus efectos, contribuye a aumentar la complejidad del riesgo, creando nuevas incertidumbres.

Partiendo del ejemplo del Valle de Los Chillos, este artículo pretende mostrar cómo la exploración de las diferentes formas de complejidad, y su formalización, permite evidenciar las incertidumbres y sus implicancias en términos de vulnerabilidad. Esta reflexión se sitúa en un momento de cuestionamiento de las políticas de reducción de los riesgos. En efecto, numerosos autores insisten hoy en día sobre el hecho de que reducir el riesgo requiere actuar en situación de incertidumbre (Godard et al., 2002), lo que justifica entonces la búsqueda de soluciones más reactivas, basadas en particular sobre el refuerzo de la defensa civil. Por ende, desenmarañar la complejidad es un paso previo a la reducción de las incertidumbres, fuentes de la vulnerabilidad, para así contribuir a reducir la frecuencia y la intensidad de los futuros desastres.

El riesgo asociado al volcán Cotopaxi en el Valle de Los Chillos parece ser a priori cuantificable, como se presenta en la primera parte del artículo. Esto parece concordar con las definiciones del riesgo, sobre todo las de los aseguradores, que suponen la posibilidad de un cálculo de probabilidades. Sin embargo, las fuentes de incertidumbre ligadas a la complejidad del riesgo son múltiples, lo que se destaca en la segunda parte. Las modificaciones actuales, ligadas a la urbanización creciente o al retroceso del glaciar que da origen a los lahares'1, nos llevan a relativizar las enseñanzas deducidas de los eventos pasados. Por otro lado, las divisiones administrativas obstaculizan la implementación de una política global de reducción del riesgo. En fin de cuentas, los esfuerzos de cuantificación se enfrentan a la complejidad del riesgo, que yace por ejemplo en la variedad de los tipos de población expuesta. La complejidad aquí reconocida cuestiona el enfoque clásico del riesgo y de su gestión, y nos conduce a la necesidad de actuar en situación de incertidumbre. En ese contexto, el refuerzo de la capacidad a manejar crisis puede contribuir a aumentar la resiliencia de las sociedades locales - es decir su capacidad para conservar las estructuras fundamentales cuando ocurre un evento perturbador (Pigeon, 2007) - y a limitar los daños potenciales. La tercera parte será una oportunidad para desarrollar dos ejemplos de reducción de incertidumbres, a partir de las investigaciones realizadas en cooperación con las contrapartes locales. Se trata primero de la cuantificación, la caracterización y la localización de las poblaciones expuestas, y después, de la identificación de los principales centros de actividades del sector económico.

1 Flujos de lodo y de escombros provocados por el derretimiento acelerado del casquete glaciar durante una erupción. 


\section{CUANTIFICACIÓN DEL RIESGO ASOCIADO AL VOLCÁN COTOPAXI}

\section{1. Un evento raro pero de gran magnitud}

Los lahares constituyen el principal peligro capaz de ocasionar daños en el Valle de Los Chillos. Los principales factores de peligrosidad remiten a su velocidad, su fuerza y los volúmenes que pueden acarrear sobre grandes distancias. Durante la última gran erupción de 1877, los lahares del volcán Cotopaxi provocaron importantes estragos y un millar de víctimas, a pesar de haber afectado zonas rurales escasamente pobladas. En esa época, el Valle de Los Chillos desempeñaba el rol de granero para la capital. Actualmente se encuentra ampliamente urbanizado.

Los testimonios dan una idea de la magnitud de los estragos:

«El Río Pita [] se dividió en algunos brazos y devastó horriblemente este ameno valle» (Sodiro, 1877).

Por su lado, Wolf $(1878)$ ha descrito de qué manera se sintió el fenómeno hasta el litoral de Esmeraldas, a más de $250 \mathrm{~km}$ del volcán:

«... 18 horas después del principio de la catástrofe, llegó la avenida en forma de una creciente del río Esmeraldas al Océano Pacífico. [ ] los cadáveres, pedazos de casas, muebles de toda clase, árboles, etc. que flotaban en el agua turbia, anunciaron a los habitantes del litoral la desgracia que había sucedido a sus hermanos del interior...».

Además de su carácter destructor, los lahares se caracterizan por su complejidad. Una multitud de factores se deben tomar en cuenta, entre los cuales se encuentran la intensidad y la duración de la erupción, la cantidad de hielo movilizado (dependiendo de la superficie potencialmente expuesta a la caída de piroclastos), y por último, la topografía y las construcciones humanas que van a influir sobre las características del flujo.

Según el IG EPN2, se tiene información sobre diecisiete erupciones importantes a partir del año 50 a. C., de las cuales quince provocaron lahares de diferentes magnitudes. Las fuentes son diversas: levantamientos topográficos, cortes geológicos, registros históricos desde la llegada de los españoles en el siglo XVI, así como testimonios más recientes en el caso de la última erupción. El periodo de retorno de las grandes erupciones, es decir de las erupciones susceptibles de generar lahares similares a aquellos de 1877 (evento que sirve de referencia sin ser el más importante), es estimado entre 100 y 150 años.

\section{2. Un daño potencialmente importante}

Los lahares afectarían al Valle de Los Chillos, una zona periurbana de Quito (fig. 1) donde existen dos territorios político administrativos: el cantón Rumiñahui y la

2 Instituto Geofísico de la Escuela Politécnica Nacional (Ecuador). 


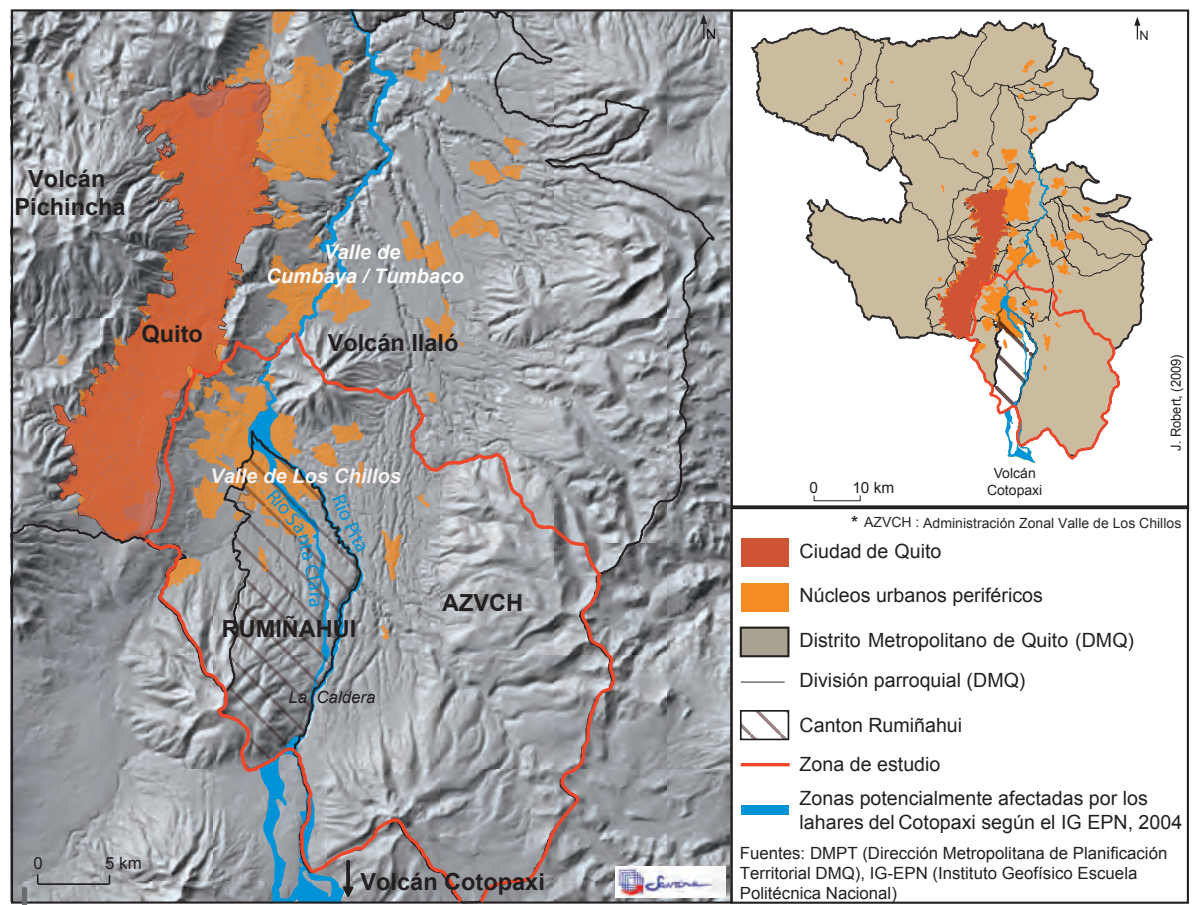

Figura 1 - Localización de la zona de estudio: el Valle de Los Chillos

Administración Zonal Valle de Los Chillos $(\mathrm{AZVCH})^{3}$. El valle ha conocido un desarrollo acelerado en los 20 últimos años, el mismo que continúa actualmente con la expansión urbana de la capital en dirección a los valles orientales particularmente atractivos.

La población Ilegaba apenas a los 20000 habitantes en 1950. Entre 1982 y 2001 se triplicó, superando actualmente los 180000 habitantes, lo que equivale al 10 \% de la aglomeración quiteña. La atracción por este sector, sobre todo por poblaciones más bien acomodadas (clases medias a altas), se explica por la búsqueda de un mejor marco de vida a proximidad de la capital: menor altura (cerca de 2600 m, o sea 200 m menos que Quito), clima más agradable, espacios verdes y ríos, etc. Aquí se desarrollan empresas, y los parques, jardines y casas ofrecen un marco agradable, generando un sentimiento de seguridad. Es difícil imaginar entonces la fuerza de destrucción de los lahares que, durante la última erupción, se encauzaron por los riachuelos Santa Clara y Pita, transportando bloques del tamaño de un automóvil. Este sentimiento de seguridad se refuerza por el alejamiento del volcán, situado a más de $40 \mathrm{~km}$ al sur, e invisible en gran parte del Valle de Los Chillos. Por otro lado, las numerosas edificaciones

3 La AZVCH es una de las ocho administraciones zonales del Distrito Metropolitano de Quito (DMQ). 
e inversiones realizadas en estos últimos años suscitan cierto escepticismo en cuanto a la existencia real de un riesgo. Al mismo tiempo, el crecimiento urbano se acompaña de la ocupación y de la densificación de las zonas expuestas (fig. 2), a pesar del reconocimiento del riesgo, por lo menos por parte de los científicos y de los responsables políticos. Entre los lugares estratégicos, «El Triángulo», centro neurálgico del Valle de Los Chillos donde desemboca la autopista proveniente de Quito, se sitúa en zona expuesta. Lugar central de comunicación y de actividades, también se ubica en la intersección de las dos administraciones.

Como consecuencia de esta urbanización acelerada, más de 15000 residentes están directamente expuestos a lahares según la zonificación del IG EPN (2004), es decir más del 8 \% de la población total del Valle de Los Chillos . La mayoría, más de 9000 personas, se encuentra en el territorio de Rumiñahui (14\% de la población del cantón), en San Rafael y Sangolquí. Los otros 6000 se encuentran en la Administración Zonal Valle de Los Chillos, representando $5 \%$ de su población.

\section{3. ¿Hacia una cuantificación del riesgo?}

Según la definición clásica del riesgo, que lo considera como el producto de la amenaza y de la vulnerabilidad, se podría proponer su cuantificación. La amenaza es definida a partir de la estimación del periodo de retorno de un evento de magnitud conocida, en este caso la erupción de 1877. Bastaría entonces con evaluar los daños potenciales, sobre la base de la extensión espacial del fenómeno (información igualmente conocida).

La evaluación del riesgo presentada aquí se basa en los dos tipos de enfoques clásicamente utilizados de manera combinada (Dubois-Maury \& Chaline, 2002). Un primer enfoque determinista se fundamenta sobre un conjunto de datos objetivos relativos a un sitio (en nuestro caso los depósitos de los antiguos lahares del Cotopaxi). Este permite identificar la extensión espacial de los eventos históricos. De manera complementaria, el enfoque probabilista, utilizado con frecuencia por los aseguradores para optimizar sus estrategias, tiene como objetivo evaluar la probabilidad de ocurrencia de los eventos en función de su intensidad. Ahora bien, tal como lo precisan Godard et al., el riesgo, a diferencia de la incertidumbre, supone estar limitado por una distribución de probabilidades objetivas. Entonces puede ser calificado de riesgo comprobado. En el caso contrario, solo se trata de un riesgo potencial o incertidumbre, que designa las situaciones que escapan a las probabilidades objetivas. Es el caso cuando no se puede definir las probabilidades de todos los resultados posibles, o cuando existe una parte desconocida y de ignorancia que se traduce en la posibilidad de sorpresa (Godard et al., 2002).

La serie estadística disponible de las erupciones del volcán Cotopaxi, limitada a diecisiete eventos notables y de magnitudes diversas, constituye un primer límite

4 En 1877, el Valle de Los Chillos tenía solamente algunos miles de habitantes; en 1982, la población expuesta era de aproximadamente 8000 habitantes (D'Ercole, 1991). 
en cuanto a la validez de un enfoque probabilista del riesgo. Ahora bien, otros factores cuestionan tal interpretación del riesgo (probabilista y determinista), señalando sus numerosas limitaciones.

\section{LA EVALUACIÓN DEL RIESGO CUESTIONADA POR EL RECONOCIMIENTO DE LAS INCERTIDUMBRES}

\section{1. Complejidad del fenómeno «lahar»}

\section{1. 1. Un conocimiento limitado de la amenaza}

Los científicos son los primeros en reconocer la complejidad del fenómeno de lahar. En una advertencia a las autoridades que figura en la reseña del mapa de las amenazas del Cotopaxi se puede leer:

«Se debe aclarar que los límites de las zonas de peligro son aproximados y que de ninguna manera constituyen límites absolutos. Esto se debe a que los fenómenos eruptivos pueden variar enormemente en su magnitud, su alcance y su volumen, y por lo tanto en su extensión lateral y longitudinal» (Hall et al., 2004).

Además, los parámetros que originaron los lahares de 1877 han cambiado mucho, como la cantidad de hielo disponible. Los estudios realizados en el Nevado del Ruiz (Pierson et al., 1990) han permitido estimar que aproximadamente $10 \%$ de la cantidad de hielo disponible es movilizada por la exposición a los flujos piroclásticos. También muestran claramente que la superficie del glaciar constituye el factor principal que condiciona el volumen de los lahares. En el caso del Cotopaxi, esta superficie ha disminuido en un $40 \%$ entre 1976 y 20065, lo que constituye un factor importante de reducción del riesgo.

La magnitud de los lahares depende también de la intensidad eruptiva. De las diecisiete erupciones de gran magnitud (VEI6 $\geq 3$ ) conocidas desde el año 50 a. C., nueve alcanzaron un índice de explosividad volcánica igual a 4, como la erupción de 1877. Seis fueron de una magnitud inferior y dos fueron superiores (hacia 150 y 950 d. C.). Los científicos contemplan además tres escenarios. La probabilidad del escenario tomado en cuenta para la zonificación (escenario n. ${ }^{\circ} 2$ ), que corresponde a una erupción del tipo de la de 1877 (VEI=4), es de $60 \%$ una vez que se inicia el proceso eruptivo (Samaniego et al., 2004). Es de $30 \%$ en el caso de una erupción que provoque lahares de menor tamaño en comparación con los de 1877 (escenario n. ${ }^{\circ}$ 1) y de $10 \%$ en el caso del escenario de mayor magnitud

5 Información entregada por É. Cadier (IRD) en el marco de la presentación «Segunda campaña de mediciones de los glaciares del volcán Cotopaxi» durante el seminario «El volcán Cotopaxi y los riesgos asociados», Quito, 2007.

6 El VEI (Volcanic Explositivity Index) da una medida relativa de la explosividad de los volcanes expresada mediante una escala que va de 0 (erupción no explosiva) a 8 (erupción extremadamente explosiva). 
(escenario n. ${ }^{\circ}$ 3). Sin embargo, las limitaciones de la serie estadística vuelven estos porcentajes muy aproximativos.

Los volúmenes estimados varían del 1 al 10 en función de la intensidad eruptiva del evento. Con 15 millones de $\mathrm{m}^{3}$ en el escenario $\mathrm{n} .^{\circ} 1$, los lahares provocarían ya daños importantes. Sin embargo, estos serían bastante menores en comparación con los de 1877 (aproximadamente 60 millones de $\mathrm{m}^{3}$ ) o a los lahares potencialmente generados por el escenario $n .^{\circ} 3$, cuyo volumen se estima en 120 millones de $\mathrm{m}^{3}$. Este último escenario tampoco se puede comparar con erupciones prehistóricas conocidas del Cotopaxi. Más explosivas y más peligrosas, estas erupciones son capaces de generar lahares de extraordinaria magnitud, como el denominado Enormous Chillos Valley Lahar (Mothes et al., 1998), cuyo volumen superó el millar de millones de $\mathrm{m}^{3}$. La magnitud se explica también por el tamaño del glaciar que era más importante en esa época. Este evento, acaecido hacia 2550 a. C., es considerado como el más importante de este tipo en el norte de los Andes.

Así, la fecha de la próxima erupción, su intensidad y la magnitud de los lahares potenciales son difícilmente previsibles, mostrando los límites de la interpretación científica que busca cuantificar el riesgo.

\section{1. 2. La urbanización, factor de modificación y de transferencia de riesgo}

Las modificaciones de la topografía, provocadas por una urbanización sin precedente (fig. 2), aparecen como un nuevo factor de complejidad y de incertidumbre. El atractivo de la zona así como una voluntad de desarrollo claramente manifestada (y como veremos, diferenciada en función de las administraciones presentes), han favorecido las edificaciones sobre los sectores históricamente afectados por los lahares. Estas construcciones, a veces de gran tamaño, son susceptibles de modificar las condiciones de evacuación de los lahares, desviándolos o canalizándolos. Consciente del problema, el IG EPN tiene proyectado realizar una modelización que tome en cuenta estas infraestructuras.

El centro comercial San Luis Shopping es el ejemplo tipo de ello (fig. 3). Esta edificación de aproximadamente 500 m de largo está situada en la confluencia de los dos brazos de lahares (fig. 2), frente al volcán. Actualmente, es uno de los mayores centros comerciales de la región y se beneficia de una situación favorable asociada al atractivo de la zona y a una demanda creciente por este tipo de servicios, por parte de las clases medias mayoritariamente representadas. Sin embargo, está situado en una zona expuesta. Paradójicamente, la adquisición de los terrenos fue facilitada por la mini crisis del Cotopaxi en 2001-20027, que favoreció el descenso de los precios de los terrenos y el abandono de las propiedades en algunos sectores. Pero al mismo tiempo, esta inversión es percibida por algunos como la prueba de la ausencia de riesgo, pues un centro comercial de esta envergadura solo puede

7 Aumento anormal de la actividad sísmica entre noviembre de 2001 y enero de 2002. El Cotopaxi no había mostrado señales de actividad desde 1975 (IG EPN). 

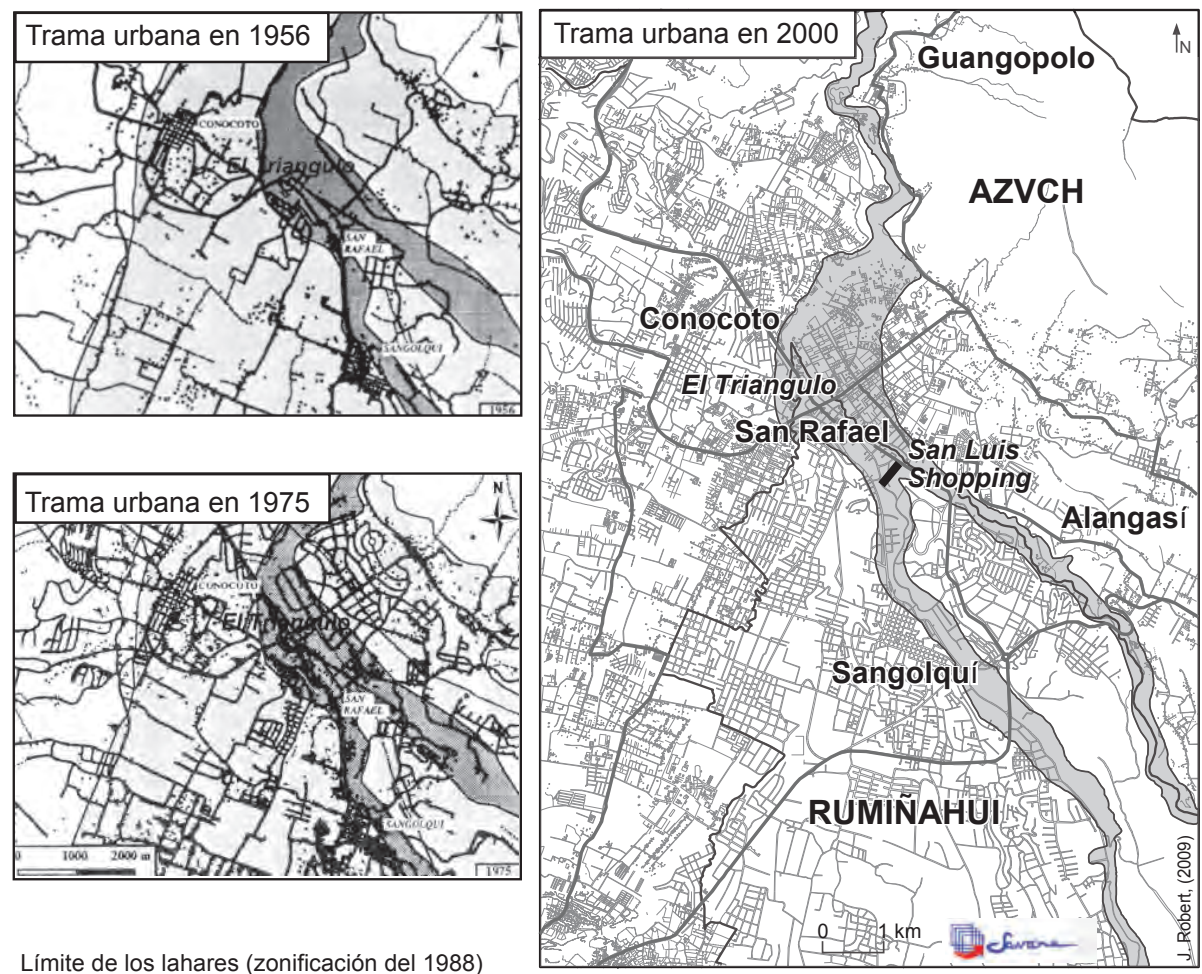

Límite de los lahares (zonificación del 1988)
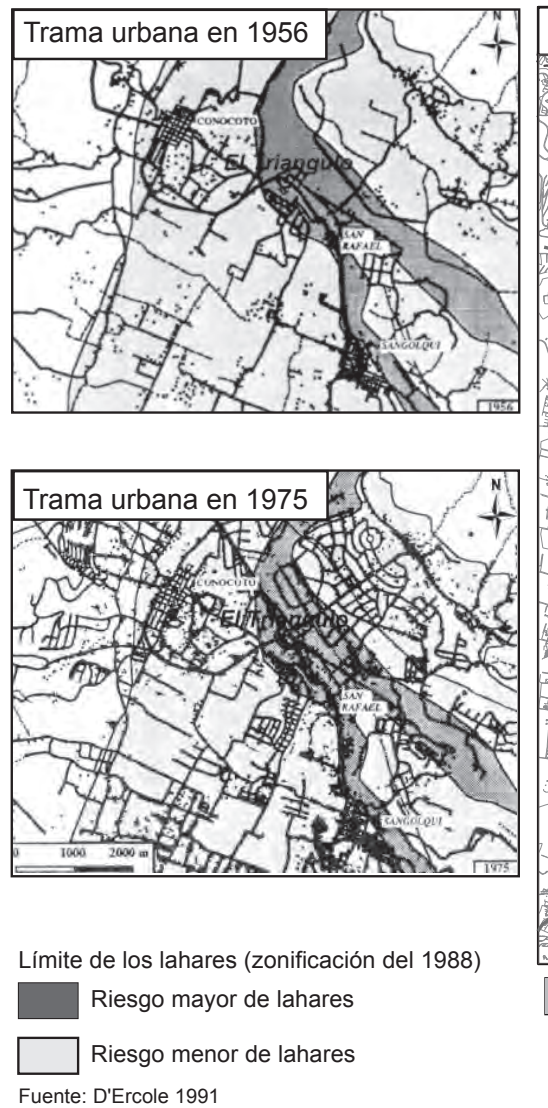

$\begin{array}{ll}- & \text { Límites administrativos } \\ \text { Red vial principal } & \text { - San Luis Shopping } \\ \text { Trama urbana } & \text { Fuente: INEC 2001, DMPT }\end{array}$

Figura 2 - Evolución de la urbanización de 1956 a 2000 en el Valle de los Chillos

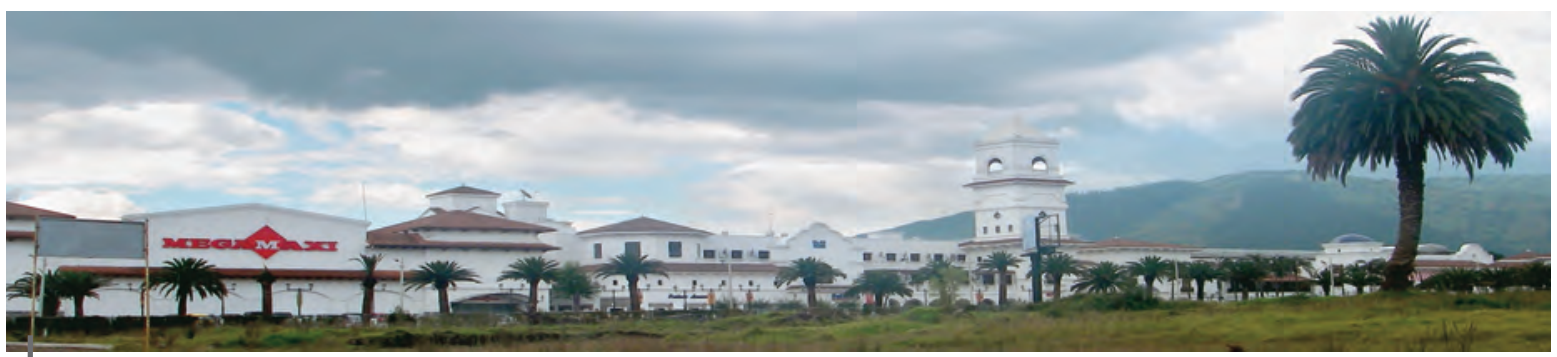

Figura 3 - Centro Comercial San Luis Shopping en el Valle de Los Chillos

Foto: T. Serrano, 2007 
haber sido construido con conocimiento de causa. Su presencia refuerza de cierta manera el sentimiento de seguridad ya observado en el sector.

Sin embargo, esta construcción provoca un aumento directo del riesgo. Como si fuese un dique de contención de los lahares, el centro comercial es susceptible de modificar su trayectoria provocando un desvío de los flujos. Cuestiona así la validez de la zonificación. Por otro lado, genera un aumento de la frecuentación de población en zona expuesta y, al representar un nuevo atractivo en la zona, tiende a intensificar su urbanización.

Los conocimientos limitados de la amenaza se añaden por ende a las modificaciones actuales de la topografía. Las incertidumbres que resultan de ello están ilustradas en la elaboración de los mapas de zonificación.

\section{2. Las incertidumbres ligadas a la zonificación}

\section{2. 1. Evolución de la zonificación en el tiempo y según las instituciones}

La zonificación propuesta en 2004 por el IG EPN8 está basada en la extensión de los lahares generados por la última gran erupción de 1877 y solo representa una referencia. Los mismos científicos insisten en las limitaciones de este documento, así como en la importancia del proceso de negociación que ha provocado. En efecto, esta zonificación reemplaza a la realizada en 1988 (Hall \& Hillebrandt, 1988)9. Esta última tomaba en cuenta una zona de riesgo menor mucho más amplia, correspondiente al denominado Enormous Chillos Valley Lahar, y que comprometería actualmente a 60 \% de la población del Valle de Los Chillos. La muy escasa probabilidad de ocurrencia de este tipo de evento justifica la supresión de esta zona de la actual zonificación. Además, el retroceso del glaciar, ampliamente mediatizado en el contexto actual del calentamiento climático, refuerza esta decisión que concuerda con los intereses políticos y económicos de la región. A propósito de la erupción de 1877, Wolf observaba sin embargo que tan solo una pequeña parte del glaciar se había fundido:

«las masas de hielo que se han conservado todavía, serían suficientes para ocasionar al menos diez inundaciones similares a la del 26 de junio» (Wolf, 1878).

A pesar de las incertidumbres, esta nueva versión de la zonificación excluye los desastres de frecuencia rara y de intensidad máxima. Por otro lado, cada una de las dos administraciones utiliza una zonificación diferente. La AZVCH utiliza la

8 El IG EPN está oficialmente reconocido por Decreto Ejecutivo como la institución científica encargada de «la identificación de las amenazas volcánicas y sísmicas y la preparación de los mapas de peligro respectivos».

9 El mapa de Hall \& Hillebrandt, a 1/50.000, se inspira en un mapa anterior a 1/100.000 realizado por Usaid en 1978 (equipo C. Miller, D. Mullineaux y M. Hall) después de señales de reactivación del volcán en 1975 y 1976. 
zonificación del IG EPN, y el cantón Rumiñahui, la de la ESPE10 (fig. 4). Los métodos usados también varían: levantamientos topográficos y testimonios históricos en el primer caso, modelización en el segundo. Los límites de las zonas expuestas difieren sensiblemente $y$, sean cuales fueran los métodos utilizados, persisten numerosas incertidumbres. Esta falta de coherencia entre referencias científicas pone en duda la credibilidad otorgada a las autoridades. También es directamente contraproducente en términos políticos de prevención del riesgo y de preparación de las poblaciones. Por ejemplo, existen zonas de albergue identificadas por las autoridades de Rumiñahui que, además de no ser conocidas por las autoridades del AZVCH, se encuentran en zona expuesta según la zonificación del IG EPN. Por consiguiente, estas confusiones se transmiten a la población.

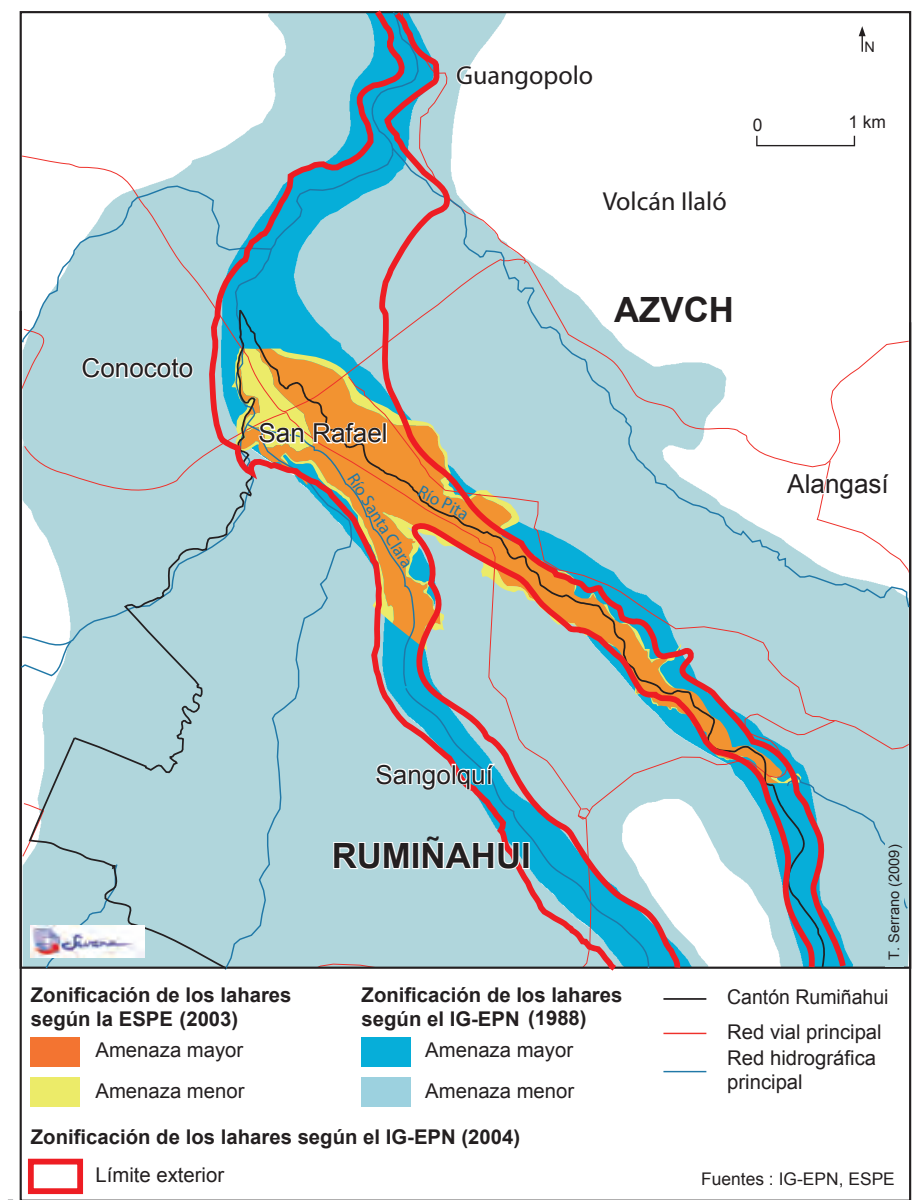

Figura 4 - Las diferentes zonificaciones de los lahares del Cotopaxi

10 Escuela Superior Politécnica del Ejército, situada en el cantón Rumiñahui. 
Las controversias en cuanto a los límites de las zonificaciones, además de ilustrar la complejidad del riesgo y las incertidumbres asociadas, se convierten entonces en una fuente de vulnerabilidad.

\section{2. 2. Los límites de la zonificación}

A pesar de las controversias, una vez aprobada y oficializada, la zonificación es percibida como una referencia irrevocable. Los límites se consideran como certezas. Por consiguiente, cuando se trata de implementar políticas de reducción del riesgo o de preparación de las poblaciones, solamente se toma en cuenta el perímetro definido como expuesto. Sin embargo, son evidentes las insuficiencias del trazo para representar un fenómeno tan complejo como un lahar. El problema existe en otros contextos, como en los Planes de Prevención de Riesgos Naturales previsibles (PPRN) de Francia. Se trata de herramientas institucionales que permiten espacializar el riesgo y que proponen una delimitación de las zonas más o menos expuestas, asociada a una reglamentación bien definida. Aquí también los límites del riesgo están basados a priori en la supuesta exactitud de los estudios científicos, pero generalmente son el resultado de una negociación, porque una vez trazado, el límite tiene valor jurídico. Varios ejemplos recientes tienden a matizar las zonificaciones. Por ejemplo, para el riesgo de avalancha de nieve, existe desde hace poco una zona de Avalancha Máxima Verosímil (AVM), para la cual se debe organizar un plan de evacuación. Esta induce así un margen de seguridad, y el hecho que esta no impone prescripciones en términos de urbanización, la hace más fácilmente aceptable. Al mismo tiempo esta permite mostrar el riesgo y prever eventos excepcionales.

El hecho de establecer un límite que separa espacialmente el riesgo del no riesgo puede, en consecuencia, dar origen a varias interpretaciones. En el caso de la zonificación del Valle de Los Chillos, además de generar un sentimiento de seguridad y una fe en la exactitud científica, tiende a afianzar a los responsables políticos en la idea de que no puede existir sino un solo evento, tal como aparece en el mapa, limitando así las capacidades de reacción. En efecto, la atención se centra en la zona considerada como expuesta (en términos de elementos de riesgo, de preparación, de identificación de las zonas de albergues, etc.) cuando potencialmente los daños pueden alcanzar una zona mucho más vasta, como los sectores que pueden encontrarse aislados entre los brazos del río Pita y del río Santa Clara.

Ahora bien, como lo han mostrado los estudios sobre la percepción del riesgo (Salazar, 2008; Salazar y D’Ercole, en este volumen, pp. 849-871), la población tiene también su propia visión de las zonas expuestas. Esta puede, o no, coincidir con la zonificación científica. Algunas personas se consideran expuestas a pesar de encontrarse fuera de los límites propuestos por los científicos, y viceversa. Además, en caso de crisis, es la población que va a ser afectada, y su comportamiento está directamente ligado a su percepción del riesgo y de las zonas susceptibles de ser afectadas. 
La divergencia entre los puntos de vista de científicos, autoridades municipales y poblaciones, aparece como un factor de vulnerabilidad y tiende a limitar la eficacia de las políticas de gestión del riesgo, las cuales dependen también de las divisiones administrativas.

\section{3. Las políticas de gestión del riesgo: materialización de las incertidumbres}

Las incertidumbres en cuanto a la ocurrencia y la amplitud de los fenómenos potenciales influyen en las decisiones políticas: dada la escasa frecuencia del riesgo, este último es minimizado, incluso ocultado, particularmente para permitir el desarrollo urbano. La situación es aún más compleja debido a que dos entidades administrativas distintas actúan en el Valle de Los Chillos.

\section{3. 1. Confrontación de dos territorios distintos}

El Valle de Los Chillos es el lugar de confrontación de dos territorios administrativos (fig. 1) con realidades completamente diferentes, por sus tamaños, sus medios y sus intereses. La expansión de la aglomeración urbana de Quito, dentro del Distrito Metropolitano de Quito (DMQ), limita aquí con el territorio del cantón Rumiñahui. Los flujos y los intercambios no dejan de amplificarse, favoreciendo la integración de este cantón en el sistema urbano quiteño. Al mismo tiempo, Rumiñahui desea afirmar su autonomía y constituye un verdadero enclave de aproximadamente 66000 habitantes en el seno del DMQ, que cuenta con cerca de dos millones de habitantes. Dos lógicas se oponen entonces, y cada una de las dos administraciones adopta su propia política, generando distorsiones en materia de gestión del riesgo.

\section{3. 2. Las políticas de planificación}

En la AZVCH, las políticas de ocupación del suelo imponen un uso residencial de escasa densidad en las zonas expuestas (fig. 5). Esto se traduce por exigencias tales como el tamaño de las parcelas fijado en 1000 m², o también el número de pisos de las edificaciones limitado a dos en las zonas expuestas a los lahares, pudiendo llegar a tres solo a partir de cierta distancia. Se hace una excepción en el caso de las avenidas principales, en las que se autoriza construcciones de cuatro pisos.

Al contrario, el cantón Rumiñahui es mucho más dependiente de inversiones externas y de sus repercusiones fiscales. El discurso actual de las autoridades del cantón consiste en favorecer el desarrollo de empresas y de comercios, limitando la ocupación residencial considerada como la única vulnerable frente al riesgo (Serrano \& Demoraes, 2007). Las exigencias son, por ende, menores en comparación con la AZVCH. El tamaño mínimo de las parcelas puede llegar a $50 \mathrm{~m}^{2}$, el número de pisos está limitado a 3 en zona expuesta, y existen numerosas zonas, sobre todo entre los dos brazos de lahares, en los que se autorizan inmuebles de 4 pisos. 


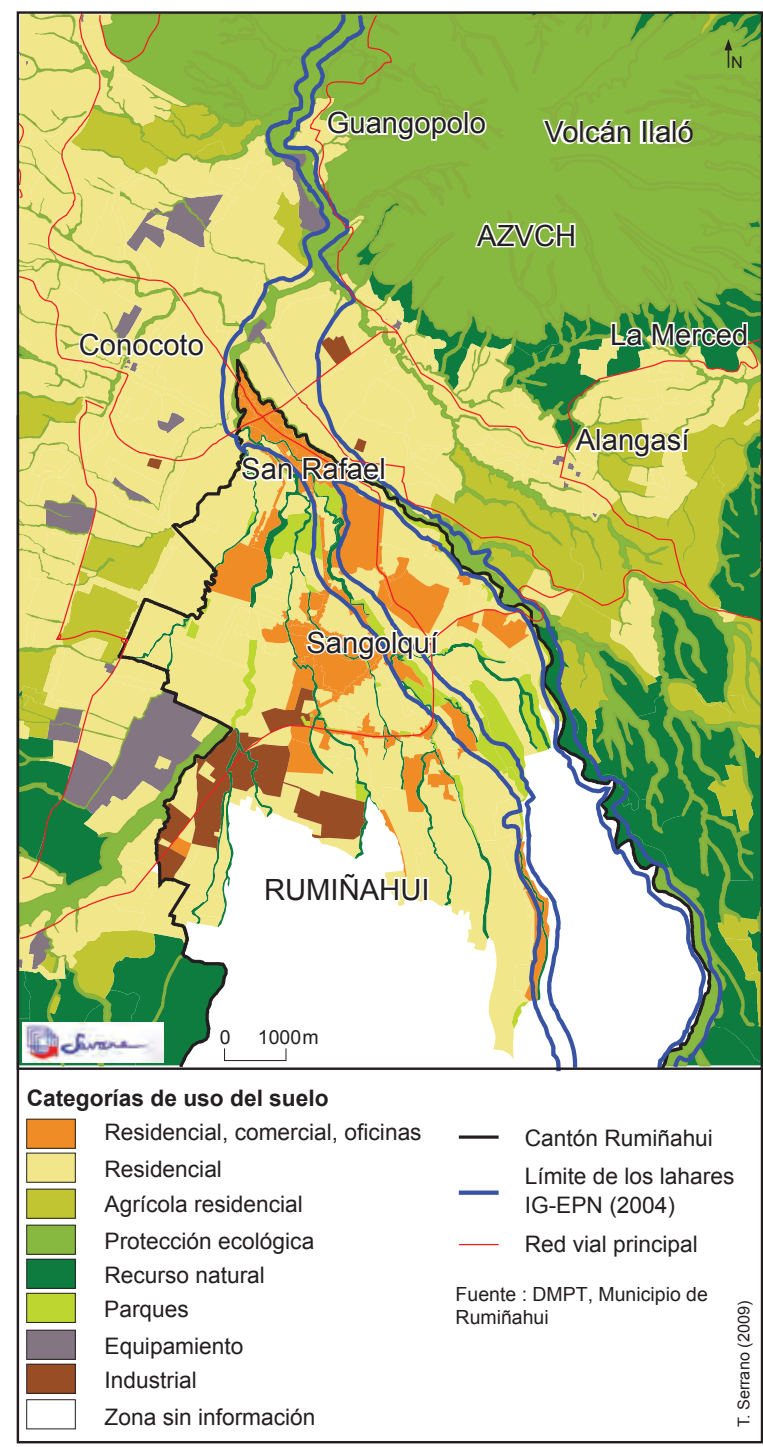

Figura 5 - Uso del suelo en el Valle de Los Chillos en 2007

Las diferencias de las políticas de planificación del uso y ocupación del suelo se explican en parte por el posicionamiento de las dos administraciones en el sistema urbano quiteño. La AZVCH es dependiente del DMQ, pero, en contraparte, se beneficia de su apoyo financiero. El cantón Rumiñahui es independiente en términos de gestión pero permanece ligado al DMQ que genera importantes flujos migratorios y económicos. No es una casualidad que el desarrollo urbano de Rumiñahui esté dirigido hacia Quito. Este aprovecha la proximidad de los ejes de comunicación, y en particular de la autopista Rumiñahui que desemboca en el extremo norte del cantón. Además de esta dependencia, el Valle de Los Chillos, y 
sobre todo el cantón Rumiñahui, entran en competencia con el valle de Tumbaco/ Cumbaya (fig. 1), donde la urbanización también se intensifica, particularmente con la construcción del nuevo aeropuerto. El riesgo y los elementos estrátegicos de desarrollo se confrontan entonces en un espacio restringido, y de manera mucho más acentuada en el cantón Rumiñahui.

Las diferencias de políticas de planificación preventiva se traducen por una desigual densificación de la construcción. Las zonas urbanas expuestas son también proporcionalmente más importantes en el cantón Rumiñahui. Un $30 \%$ del territorio urbano del cantón, contra solo un $7 \%$ en la AZVCH, estaría directamente expuesto o aislado en caso de erupción.

\section{3. 3. Las obras de protección}

Las políticas tratan de reducir el riesgo favoreciendo al mismo tiempo el desarrollo económico urbano, pero su eficacia es parcial, provocando modificaciones y transferencias de riesgo. Esta constatación se ilustra a través del proyecto de dique propuesto en 1997 por la ESPE y la municipalidad de Rumiñahui, que fue sin embargo abandonado. Ubicado sobre el sitio de la Caldera al sur del cantón Rumiñahui (fig. 1), el dique tenía como objetivo desviar los lahares al cauce del río Pita y proteger el cantón Rumiñahui donde se encuentran, entre otros, el hospital de Sangolquí y numerosos establecimientos escolares. Sin embargo, este habría literalmente transferido el riesgo hacia la AZVCH. Un costo prohibitivo y las presiones ejercidas por la AZVCH condujeron al abandono del proyecto.

Como se ha mostrado anteriormente, se constata que la ausencia de coordinación y la división territorial dificultan la implementación de soluciones. Las incertidumbres en materia de conocimiento del fenómeno físico, que se añaden a la escasa probabilidad de ocurrencia de un desastre, influyen directamente en las decisiones de los gestores. Por otro lado, la vulnerabilidad institucional y la eficacia parcial de las políticas de gestión del riesgo que ella genera, dan origen a nuevas incertidumbres. El desarrollo urbano de las zonas expuestas tiene consecuencias no solo sobre la amenaza (a través de la modificación de la topografía, por ejemplo), sino también sobre la frecuentación de estas zonas por parte de diferentes tipos de población.

\section{4. Complejidad ligada a los tipos de población expuesta}

La estimación de la población expuesta implica tomar en cuenta una gran diversidad de situaciones. Varios factores tienden a generar complejidad: los diferentes tipos de población que pueden frecuentar las zonas expuestas, la variedad de esta población en función de las temporalidades (de día o de noche, en semana o en fin de semana, etc.) o también los grados de exposición.

Estos factores rara vez son tomados en cuenta en las políticas de gestión del riesgo y en particular en los aspectos de manejo de crisis. Existe de hecho una fuerte incertidumbre en cuanto a la evaluación (cuantificación y caracterización) de las poblaciones expuestas. En cuanto a los tipos de población, se ha registrado en 
efecto a empleados y turistas, como también a personas que vienen a hacer sus compras en los numerosos centros comerciales presentes en la zona. Una parte de la población proviene de Quito, pero también de los pueblos aledaños. Tanto la cantidad como el tipo de poblacion varían en función de los días de la semana y de las horas del día.

Por otro lado, la exposición no se reduce al hecho de estar situado al interior de la zonificación de lahares, sino que atañe, en un sentido más amplio, a las poblaciones en riesgo, vulnerables. Estas poblaciones pueden encontrarse fuera de los límites de la zonificación, o también en condiciones de aislamiento potencial. Cerca de 7000 personas viven por ejemplo entre los dos brazos de lahares, y podrían encontrarse cercadas en caso de erupción. En menor medida, las zonas situadas al este de la trayectoria de los lahares se encontrarían aisladas respecto de Quito. La ruptura de las vías de comunicación tendría consecuencias nefastas para el acceso a los hospitales, o también en lo referente a los múltiples intercambios entre estas zonas y la capital, como por ejemplo las actividades de exportación.

Por último, como ya se mencionó, pueden existir divergencias entre los puntos de vista de los científicos y de las poblaciones, las cuales pueden traducirse en comportamientos agravantes. Así, algunas personas podrían intentar evacuar cuando en realidad no están expuestas.

Los diferentes factores de complejidad y de incertidumbres presentados — difícil cuantificación de la amenaza, mutaciones medioambientales y urbanas, límites de zonificaciones, políticas de gestión distintas, variedad de las poblaciones expuestas - obligan a relativizar la interpretación de las enseñanzas del pasado, como la validez de la zonificación actual. En consecuencia, se cuestiona el enfoque probabilista evocado en la primera parte, así como el enfoque determinista en razón de las modificaciones de las condiciones de realización de la amenaza. La interpretación clásica del riesgo ya no es suficiente y no permite proponer su gestión eficaz. Esta enfrenta numerosos obstáculos, tanto técnicos como políticos. El aporte del geógrafo puede entonces consistir en identificar y representar las incertidumbres que hacen difícil la gestión del riesgo para reducirlas en una óptica directamente operacional.

\section{LA REDUCCIÓN DE LAS INCERTIDUMBRES COMO HERRAMIENTA DE REDUCCIÓN DEL RIESGO}

\section{1. Identificación de las necesidades de los actores locales}

Los estudios de investigación realizados en 2007 por un equipo de jóvenes investigadores11 tenían por objetivo general proveer información útil para la gestión

11 Estudios realizados en el marco del programa Pacivur del IRD «Programa andino de capacitación e investigación sobre vulnerabilidad y riesgos en medio urbano», por Tania Serrano (Universidad de Montpellier III, Francia y becaria del IFEA (UMIFRE 17, CNRS-MAEE) en 2005, Diana Salazar (Pontificia Universidad Católica del Ecuador) y becaria del IFEA (UMIFRE 17, CNRS-MAEE) en 2007, y Jérémy Robert (IFEA, UMIFRE 17, CNRS-MAEE, Universidad de Savoie, Francia). 
del riesgo asociado al volcán Cotopaxi. Se efectuaron tres estudios en paralelo en el Valle de Los Chillos, abordando la vulnerabilidad de la población (Robert, 2007), la percepción del riesgo (Salazar, 2008) y la vulnerabilidad institucional (Serrano, 2007).

Estos trabajos fueron realizados en cooperación con un organismo local, la Casa Cotopaxi. Este pequeño organismo, integrado a la Jefatura de seguridad ciudadana de la AZVCH, está encargado de las acciones de sensibilización y de preparación de la población frente a una potencial erupción del volcán Cotopaxi. Creado en 2004, este constituye una representación local de las autoridades de la municipalidad de Quito y es la única experiencia de este tipo en el seno del DMQ. Dentro de sus actividades, la Casa Cotopaxi ha censado a la población en zona expuesta, ha identificado los albergues y ha realizado simulacros de evacuación. En este contexto, las investigaciones han sido orientadas en función de las necesidades de este organismo, cuyos medios humanos y financieros son limitados.

El manejo de crisis se presenta como un tema de interés mayor que corresponde a las necesidades expresadas por la Casa Cotopaxi. Frente a la eficacia parcial de las políticas de planificación preventiva y de protección tecnológica constatada en el Valle de Los Chillos, el manejo de crisis constituye un campo privilegiado para reducir el impacto de un desastre futuro. El interés que suscita está justificado por la magnitud de los problemas en caso de erupción. Aunque algunos signos precursores (aumento de la actividad sísmica, fumarolas, deformaciones topográficas, etc.) sean detectables, no es previsible el momento mismo de la erupción. Tampoco es concebible una evacuación preventiva, de consecuencias económicas y políticas difícilmente manejables, y sobre todo en razón de las incertidumbres ligadas a la duración de la fase pre-eruptiva. Solo se puede contemplar una evacuación de último minuto. Ahora bien, el IG EPN estima que los lahares llegarían al Valle de Los Chillos en unos treinta minutos. La reactividad se convierte entonces en un factor esencial y por ello, se hace necesaria la identificación de los daños potenciales y de los medios disponibles a escala local para intentar reducir el impacto de un desastre. Dentro de este contexto, los datos producidos por la Casa Cotopaxi apuntan al mejoramiento de los conocimientos que permitan el refuerzo de las capacidades locales de gestión. Presentaremos aquí dos tipos de datos: la cuantificación, la caracterización y la localización de la población expuesta, y la identificación de los principales centros de actividades del sector económico.

\section{2. Evaluación de la población expuesta}

La población es un elemento esencial de la gestión del riesgo, la cual se debe proteger prioritariamente. Por ende, la cuantificación, la caracterización y la localización de la población potencialmente expuesta a los lahares del Cotopaxi constituyen información indispensable para la implementación de acciones de reducción del riesgo, en particular cuando se trata de evacuación. Los problemas asociados a esta última son previsibles: además de un tiempo muy corto de reacción, algunas zonas expuestas son poco accesibles y/o difícilmente evacuables. En efecto, la 
presencia de los dos ríos constituye un obstáculo, y solo un número limitado de puentes permite atravesarlos. El caso de las personas que se encontrarían aisladas entre los dos brazos de lahares sería peculiar. Intentar evacuar podría resultar más peligroso que permanecer en el sitio, a pesar de las dificultades ligadas al aislamiento. Por otro lado, el hecho de que se pueda producir una erupción en cualquier momento del día, justifica el interés, incluso la necesidad, de evaluar a la población «de día», los principales lugares de concentraciones y los tipos de actividades asociadas. Esta población difiere sensiblemente de la población residente, o «de noche», obtenida a partir del censo. Nuestra atención se ha focalizado en dos lugares: por un lado, el conjunto de los establecimientos que reciben público (comercios, empresas, lugares turísticos, etc.), y por otro lado, los establecimientos «sensibles», que reciben poblaciones vulnerables y necesitan una atención particular en caso de crisis (hospitales, escuelas y colegios, etc.).

Cuadro 1 - Comparación entre la población «de día» y la población residente expuestas a los lahares del volcán Cotopaxi en el Valle de Los Chillos

\begin{tabular}{|l|c|c|c|c|c|}
\hline & \multicolumn{2}{|c|}{$\begin{array}{c}\text { Zona expuesta (según la } \\
\text { zonificación del IG EPN-2004) }\end{array}$} & \begin{tabular}{c} 
Pobla- \\
ción \\
aislada \\
(Rumi- \\
\cline { 2 - 4 }
\end{tabular} & Rumiñahui & $\begin{array}{c}\text { Total (zona } \\
\text { expuesta } \\
\text { y zona } \\
\text { aislada) }\end{array}$ \\
\hline $\begin{array}{l}\text { Población «de día» } \\
\text { en semana }\end{array}$ & 43075 & 4111 & 47186 & 11106 & 58292 \\
\hline $\begin{array}{l}\text { f. en } \\
\text { establecimientos } \\
\text { escolares }\end{array}$ & 17732 & 1645 & 19377 & 9570 & 28947 \\
\hline $\begin{array}{l}\text { Población «de día» } \\
\text { los fines de semana }\end{array}$ & 32285 & 2804 & 35089 & 853 & 35942 \\
\hline $\begin{array}{l}\text { Población residente } \\
\text { (o de noche) }\end{array}$ & 9199 & 5914 & 15113 & 6984 & 22097 \\
\hline
\end{tabular}

Fuentes: INEC (Instituto Nacional de Estadística y Censos) 2001; Robert, 2007

Se constata que la población «de día» en semana es tres veces más importante que la población residente en zona expuesta12, y dos veces más que los fines de semana (cuadro 1). Su distribución espacial varía también sensiblemente. El centro antiguo de Sangolquí y sus alrededores aparecen como una zona de fuerte concentración de población residente. La frecuentación de día también es importante ahí debido a la concentración de pequeños comercios y restaurantes, pero también de centros comerciales de mayor tamaño. En San Rafael (fig. 6), las concentraciones de día se multiplican (a veces hasta por 10) debido a la importancia de las actividades y comercios de toda clase, a los que se agregan los establecimientos escolares.

12 Consideramos como zona expuesta los sectores correspondientes a la zonificación de los lahares del IG EPN (2004). 


\section{a. Población residente (población de noche)}

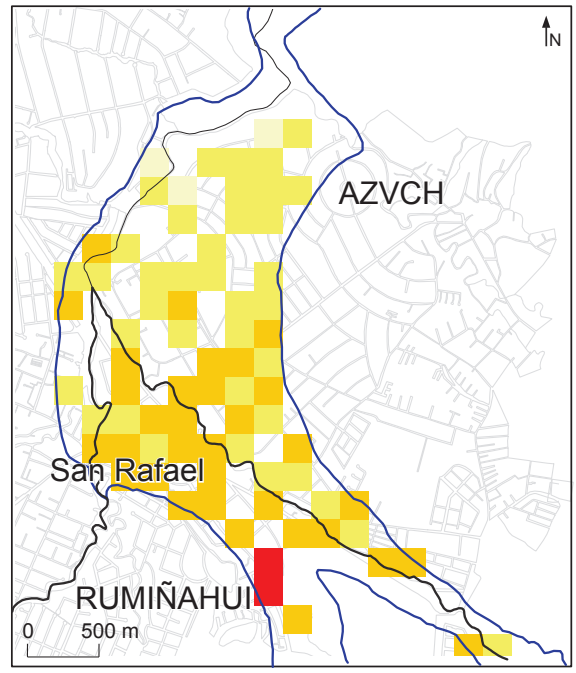

Población por celdas de $\mathbf{2 0 0} \mathrm{m}$ de lado
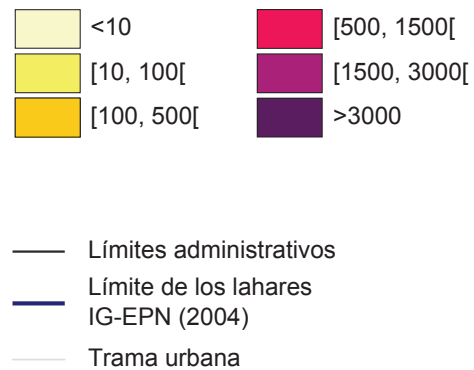

Fuente: trabajo de campo (2001), INEC 2001, DMPT

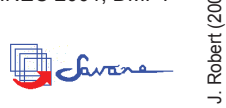

b. Población de día durante la semana

\section{c. Población de día durante los fines de semana}
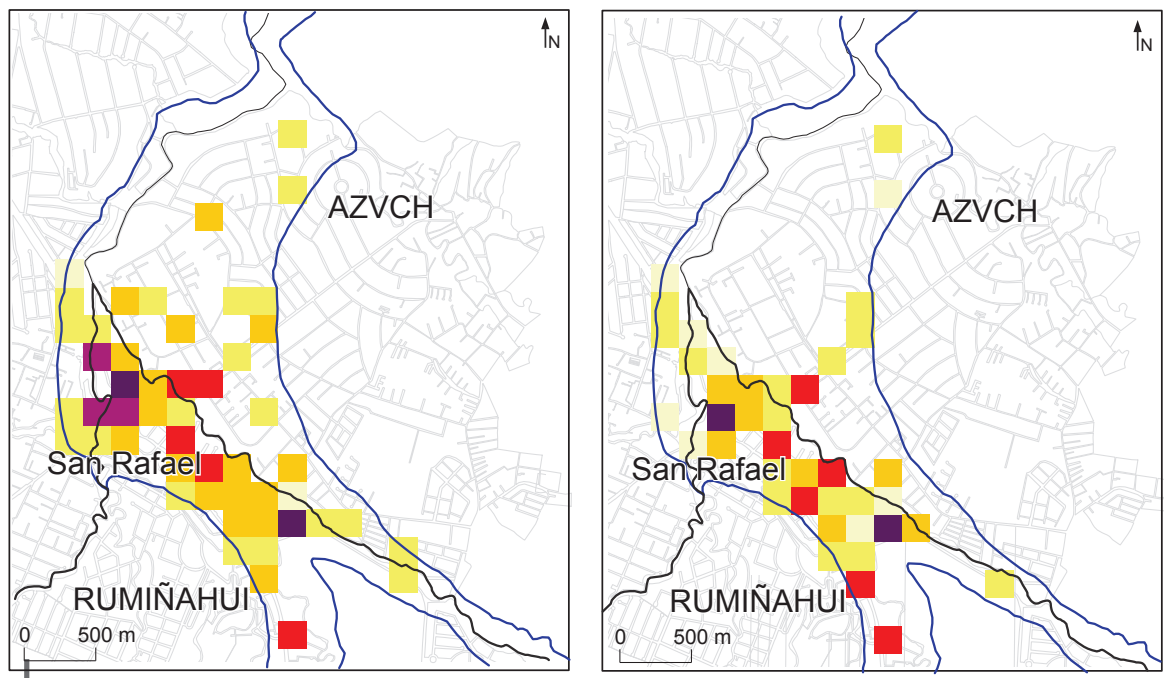

Figura 6 - Cuantificación y distribución, según el período, de la población de San Rafael expuesta a los lahares del volcán Cotopaxi

Algunos lugares de actividades generan en efecto concentraciones puntuales muy fuertes, como el centro comercial San Luis Shopping, esencialmente frecuentado de día. Este concentra a más de 8000 personas diarias en semana, y esta cifra se duplica los fines de semana. Al contrario, algunas urbanizaciones residenciales densamente pobladas de noche, están casi desiertas durante el día. Los escolares y colegiales están entre los grupos particularmente importantes. En efecto, estos representan más del cuarto de la población «de día» en semana en zona expuesta, 
o sea cerca de 17000 alumnos sobre un total de 47000 personas. Además de la gestión de una población muy joven particularmente vulnerable, es necesario prever las reacciones ocasionadas por la separación de las familias, por ejemplo: por ejemplo padres que deseen recoger a sus hijos y que podrían ponerse ellos mismos en peligro. Igualmente, la ESPE concentra más de 9000 estudiantes en una zona potencialmente aislada.

Por consiguiente, la frecuentación de día en la zona expuesta puede ocasionar una multitud de problemas diferentes. Este factor de riesgo (o más bien de incertidumbre) no había sido considerado durante la implementación de las acciones de preparación frente a una erupción del volcán Cotopaxi. Este cuestiona la validez de los criterios inicialmente tomados en cuenta, por ejemplo para la identificación de los albergues, y provee elementos de cuantificación útiles para la implementación de acciones futuras (información para la población «de día», realización de simulacros de evacuación en los centros comerciales, etc.).

\section{3. Identificación de las principales actividades del sector económico}

Sería inapropiado y reductor considerar solo la vulnerabilidad de la población. En efecto, muchos otros aspectos pueden ser tomados en cuenta, como la gestión del recurso agua (vulnerabilidad de la infraestructura situada en la trayectoria de los lahares), o también las redes de energía o de las centrales eléctricas cuyo funcionamiento podría verse en peligro. De igual manera, el hospital de Sangolquí, principal establecimiento de salud del Valle de Los Chillos, se sitúa en zona expuesta. La exposición de los elementos esenciales del funcionamiento urbano y del manejo de crisis constituye innegablemente una vulnerabilidad. Es también el caso del sector económico (esencialmente las empresas, los comercios, la restauración y el turismo) caracterizado por su dinamismo en el Valle de Los Chillos.

Entre las características del sector económico, registramos una fuerte concentración de pequeñas empresas y comercios. Se han localizado cerca de 1400 establecimientos, la mayoría de ellos en zona expuesta. Generalmente son administrados por una o dos personas que viven en el lugar. El sector de la restauración está también fuertemente representado. Más de un centenar de pequeños restaurantes se encuentran en zona expuesta, y la mayoría (excepto 20) emplean a menos de 10 personas. Por otro lado, unas sesenta empresas de mayor tamaño (más de 10 empleados) se localizan en el valle; y de ellas, 13 tienen más de 100 empleados. La mayoría de estas empresas se concentra a proximidad del centro antiguo de Sangolquí y a la altura del «Triángulo» en San Rafael (fig. 7). Este sector es uno de los más dinámicos como lo demuestra el importante número de edificios de varios pisos que están siendo construidos, en particular para oficinas. Dos «zonas industriales» aparecen un poco más alejadas: un complejo situado entre los brazos del río Pita y del río Santa Clara en el cantón Rumiñahui y, más al norte, una zona al borde del límite este de la zona expuesta a los lahares a 


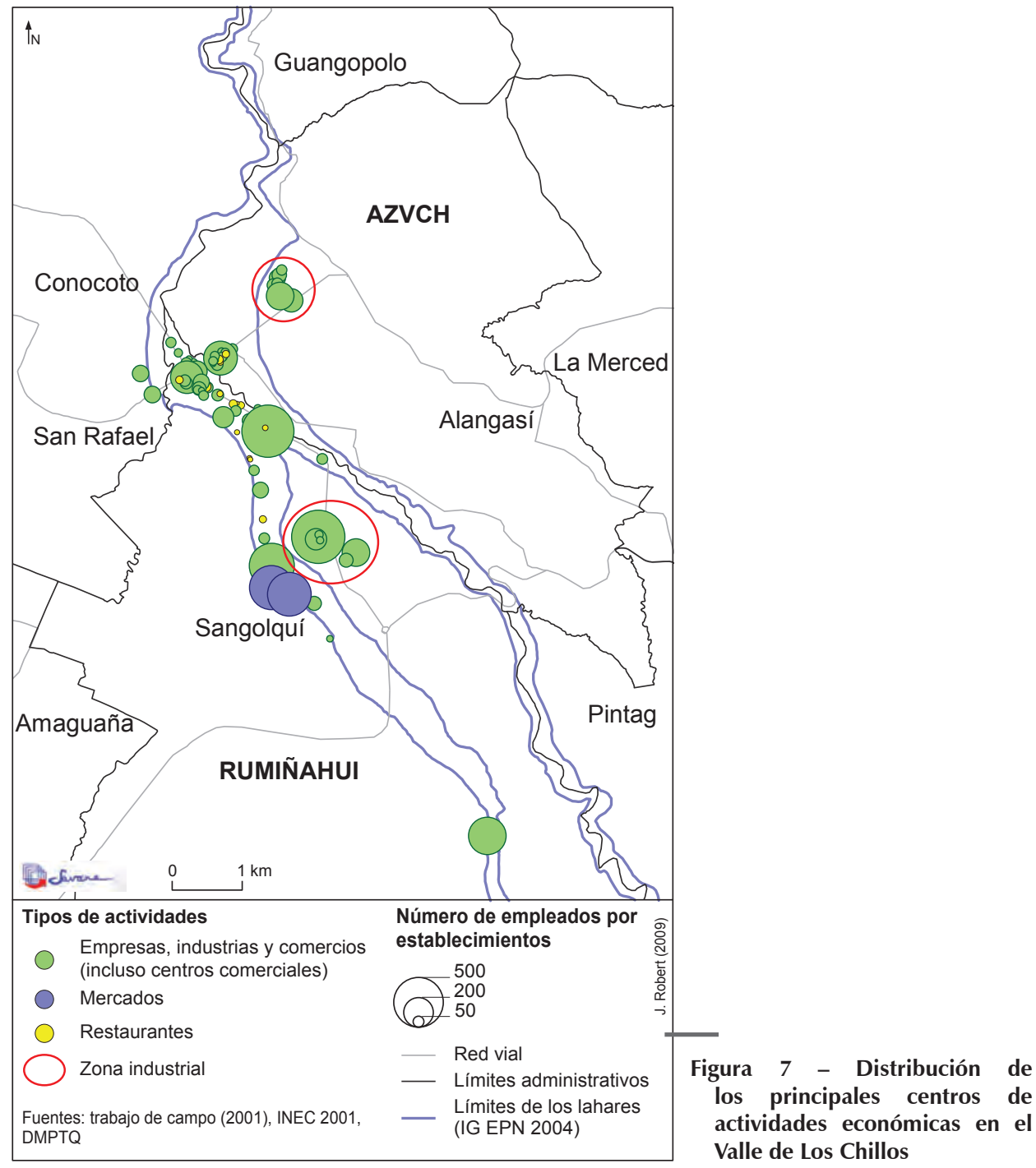

lo largo de la Avenida Ilaló. Al contrario de las pequeñas empresas y comercios centrales, la mayoría del personal de estas grandes empresas proviene de Quito (60\% de los 220 empleados de la fábrica de armas y equipos militares de Santa Bárbara, $50 \%$ de los 140 empleados de Lechera Andina y $90 \%$ de los 100 empleados de Ecuaquímica). Se trata de una población a priori poco informada sobre el riesgo asociado al volcán Cotopaxi. Los centros comerciales son también lugares de concentración importantes de personal. Los 12 centros comerciales situados en zona expuesta emplean ellos solos más de 1400 personas, de las cuales 3/4 laboran en los tres establecimientos principales: San Luis Shopping (500 empleados), River Mall (370) y Plaza Valle (196). 
El análisis de la distribución espacial de las actividades permite poner de relieve una fuerte disparidad en este campo entre el cantón Rumiñahui y la AZVCH (cuadro 2). Esta disparidad se explica en parte por las políticas de planificación actuales, en particular las de la municipalidad de Rumiñahui, que favorecen claramente la instalación de nuevas actividades. El desarrollo urbano es favorecido frente al riesgo que aparece entonces como un obstáculo.

Cuadro 2 - Cuantificación de las empresas y de la población activa situadas en zona expuesta (zonificación del IG EPN-2004, más la zona aislada)

\begin{tabular}{|l|c|c|c|}
\hline & Rumiñahui & AZVCH & Total \\
\hline $\begin{array}{l}\text { Empresas (todo tipo de } \\
\text { actividades) }\end{array}$ & $\begin{array}{c}1555 \\
\text { (sobre } 12 \% \text { del } \\
\text { territorio urbano) }\end{array}$ & $\begin{array}{c}184 \\
\text { (sobre 2,1\% del } \\
\text { territorio urbano) }\end{array}$ & 1739 \\
\hline $\begin{array}{l}\text { Personal (solamente de las } \\
\text { empresas) }\end{array}$ & 7971 & 1382 & 9353 \\
\hline $\begin{array}{l}\text { Total personal (con personal } \\
\text { escolar y medico) }\end{array}$ & 10924 & 2028 & 12952 \\
\hline
\end{tabular}

Fuentes: Robert, 2007

Como lo muestra el cuadro 2, la mayoría de las empresas (de todo tipo de actividad) se sitúa en el territorio de Rumiñahui: más de 1500 empresas y 7971 empleados potencialmente afectados en caso de erupción13 (que ocupan cerca de 300 ha, o sea $12 \%$ del total de la zona urbana) frente a menos de 200 empresas y 1392 empleados en la Administración Zonal (que ocupa 96 ha, o sea 2,1 \% de la zona urbana). Si añadimos el personal de los centros educativos y médicos, obtenemos un total de 10924 empleados en Rumiñahui, frente a menos de 2028 en la Administración Zonal, población activa en gran mayoría directamente expuesta a los lahares potenciales del volcán Cotopaxi.

El Valle de Los Chillos es también un destino apreciado del turismo recreacional. Los restaurantes de platos típicos (hornados), así como las aguas termales y piscinas atraen a un público mayoritariamente quiteño, sobre todo los días domingo. De los 12 baños termales registrados, los dos establecimientos principales, El Tingo y La Merced, pueden recibir a diario hasta 1000 personas cada uno. En promedio, aproximadamente 4500 personas frecuentan los establecimientos turísticos los fines de semana (sin considerar los restaurantes). Estas personas, así como los empleados que vienen de Quito, no son tomados en cuenta en las acciones de sensibilización y de preparación frente al riesgo pues estas están destinadas exclusivamente a la población residente y a los centros escolares. La ausencia de información contribuye a aumentar la vulnerabilidad de estos grupos de personas.

${ }^{13}$ Consideramos aquí la zona expuesta, según la zonificación del IG EPN (2004), y la zona aislada entre los dos brazos de lahares. 
El sector económico y turístico está pues concernido por el riesgo ligado al volcán Cotopaxi. Las cifras presentadas ilustran el aumento del daño potencial, caracterizado por el incremento de la población expuesta y sobre todo de la población activa, pero también de los bienes y de las infraestructuras. Los datos producidos proveen elementos de cuantificación y de localización útiles para la gestión del riesgo y el manejo de crisis.

\section{CONCLUSIONES}

El artículo muestra la necesidad de reducir la incertidumbre frente a una erupción potencial del volcán Cotopaxi, para así reducir el riesgo en el Valle de Los Chillos. Se han identificado varias incertidumbres. Estas se ven acentuadas por las mutaciones medioambientales, pero también urbanas, y por la gestión diferenciada de los territorios. Estas incertidumbres reducen el interés interpretativo y prospectivo de los eventos pasados. Es tanto más exacto por cuanto los cálculos de probabilidades ligados a los eventos volcánicos son poco confiables debido a la rareza de los eventos y a la gran variedad de las erupciones, lo que da series estadísticas a la vez de escasa frecuencia y muy heterogéneas. Estas incertidumbres obstaculizan así la cuantificación del riesgo, que a priori, parecía posible.

El reconocimiento de la complejidad del riesgo resulta entonces necesario para superar los límites de los enfoques deterministas y/o probabilistas. La identificación de los diferentes factores de complejidad, y de las incertidumbres asociadas, permite mejorar la comprensión de la vulnerabilidad. Permite también identificar los límites de las políticas preventivas de gestión del riesgo, y justifica el interés por reforzar el manejo de crisis. Este enfoque es de hecho una alternativa posible de reducción del riesgo, complementaria de un enfoque preventivo costoso en medios financieros, humanos y/o técnicos, sobre todo para la realización de obras de protección.

El refuerzo de las capacidades de manejo de crisis pasa en particular por la cuantificación actualizada de la población y de los elementos expuestos, lo que permite reducir algunos factores de incertidumbre, por ejemplo con la evaluación del monto de las pérdidas económicas y humanas esperadas en el caso de un escenario dado. Estos procedimientos prospectivos son preconizados actualmente por varios programas de investigación, como el programa europeo Scenario ${ }^{14}$. Estos aportes pueden contribuir en reforzar la gestión preventiva de futuros desastres, esperando reducir las pérdidas humanas.

Además, el refuerzo de las capacidades locales de manejo de crisis es fundamental, como lo ilustra el trabajo realizado con la Casa Cotopaxi. Este principio es valorizado por otros programas internacionales, como Microdis15, y está ampliamente

\footnotetext{
14 Programa europeo sobre la reducción de la incertidumbre y la previsión de los desastres en el que están involucradas las Universidades de Roma, Berlín, Nápoles, Lancaster y el Instituto Politécnico de Milán.

15 Programa euroasiático sobre la gestión preventiva de los desastres que involucra a las Universidades de Lovaina La Nueva, Greenwich, Newcastle, Dacca, Kuala-Lumpur, Delhi y el Banco Mundial.
} 
difundido en la bibliografía internacional (Birkmann, 2006; Wisner et al., 2007). El refuerzo de las capacidades locales reduce la necesidad de recurrir a la ayuda exterior, así como la mortalidad esperada; dos criterios tomados en cuenta para la definición de los desastres por parte de numerosos especialistas del riesgo.

\section{Referencias citadas}

BIRKMANN, J. (ed.), 2006 - Measuring vulnerability to natural hazards: towards disaster resilient societies, 524 pp.; Bonn: UNU Press.

D'ERCOLE, R., 1991 - Vulnérabilité des populations face au risque volcanique. Le cas de la région du volcan Cotopaxi (Équateur), 460 pp.; Grenoble: Université Joseph Fourier. Thèse de doctorat.

D’ERCOLE, R., GLUSKI, P., HARDY, S. \& SIERRA A., 2009 - Vulnérabilités urbaines dans les pays du Sud. Présentation du dossier - Cybergeo : European Journal of Geography. [En ligne] Dossiers, Vulnérabilités urbaines au sud, URL : http://www.cybergeo.eu/ index22151.html, 4 pp.

DUBOIS-MAURY, J. \& CHALINE, C., 2002 - Les risques urbains, 208 pp.; París: Armand Colin. Deuxième Édition.

GODARD, O., HENRY, C., LAGADEC, P., MICHEL-KERJAN, E., 2002 - Traité de nouveaux risques, 620 pp.; París: Ed. Gallimard.

HALL, M., MOTHES, P., SAMANIEGO, P., YEPES, H. \& ANDRADE, D., 2004 - Mapa Regional de los Peligros Volcánicos Potenciales del Volcán Cotopaxi - Zona Norte; Quito-Ecuador: Instituto Geográfico Militar, Instituto Geofísico de la EPN.

MOTHES, P., HALL, M. \& JANDA, J. P., 1998 - The enormous Chillos Valley Lahar: an ash-flow-generated debris flow from Cotopaxi Volcano, Ecuador. Springer-Verlag, Bulletin of Volcanology, 59: 233-244.

PIERSON, T. C., JANDA, R. J., THOURET, J.-C. \& BORRERO, C. A., 1990 - Perturbation and melting of snow and ice by 13 November 1985 eruption of Nevado del Ruiz, Colombia and consequent mobilization, flow and depositions of lahars. Journal of Volcanology and Geothermal Research, 41: 17-66.

PIGEON, P., 2007 - L'environnement au défi de I'urbanisation, 192 pp.; Rennes: PUR.

ROBERT, J., 2007 - Vulnérabilité de la population exposée aux lahars du volcan Cotopaxi dans le Valle de Los Chillos, Quito-Equateur, 97 pp.; Grenoble: Université de Savoie. Mémoire de Master II Recherche.

SALAZAR, D., 2008 - Percepción de amenazas y riesgos de la población del Valle de Los Chillos (Ecuador) frente a una potencial erupción del volcán Cotopaxi, 187 pp.; Quito: IFEA, IRD, PUCE. Informe de licenciatura.

SAMANIEGO, P., MOTHES, P., SCHILLING, S., HALL, M., YEPES, H. \& AGUILAR, J., 2004 - LAHARZ hazard maps of the Northern Drainage of Cotopaxi Volcano, Ecuador. Pucón, Chile: IAVCEI General Assembly 2004-Nov. 14-19.

SERRANO, T., 2007 - La gestion du risque lié aux lahars du volcan Cotopaxi dans la vallée de Los Chillos (Équateur). Mise en évidence de facteurs institutionnels de vulnérabilité, 105 pp.; Montpellier: Université Paul Valéry, Montpellier III. Rapport de stage Master II, Gestion des catastrophes et risques naturels.

SERRANO, T. \& DEMORAES, F., 2007 - Discrepancias institucionales y vulnerabilidad 
Complejidad, incertidumbre y vulnerabilidad: el riesgo asociado al volcán Cotopaxi (Quito, Ecuador)

asociada en el valle de Los Chillos frente al peligro de lahares del volcán Cotopaxi. Ponencia presentada en el Congreso latinoamericano de ciencias sociales en conmemoración de los 50 años de la Flacso. Simposio III «Gestión del riesgo y sus relaciones con los procesos y la gestión ambiental en los países andinos», 29-31 octubre de 2007 .

SODIRO, L., 1877 - Relación sobre la erupción del Cotopaxi acaecida el día 26 de junio de 1877, 41 pp.; Quito: Imprenta Nacional.

WISNER, B., BLAIKIE, P., CANNON, T. \& DAVIS, I., 2007 - At risk, 471 pp.; Londres \& Nueva York: Ed Routledge.

WOLF, T., 1878 - Memoria sobre el Cotopaxi y su última erupción, 48 pp.; Guayaquil: Imprenta El Comercio. 